\section{Review}

https://doi.org/10.1631/jzus.B2000479
Check for updates

\title{
Comparison of COVID-19 and influenza characteristics
}

\author{
Yu BAI, Xiaonan TAO ${ }^{\bowtie}$ \\ Department of Respiratory and Critical Care Medicine, Union Hospital, Tongji Medical College, Huazhong University of Science and Technology, \\ Wuhan 430022, China
}

\begin{abstract}
The emergence of coronavirus disease 2019 (COVID-19) not only poses a serious threat to the health of people worldwide but also affects the global economy. The outbreak of COVID-19 began in December 2019, at the same time as the influenza season. However, as the treatments and prognoses of COVID-19 and influenza are different, it is important to accurately differentiate these two different respiratory tract infections on the basis of their respective early-stage characteristics. We reviewed official documents and news released by the National Health Commission of the People's Republic of China, the Chinese Center for Disease Control and Prevention (China CDC), the United States CDC, and the World Health Organization (WHO), and we also searched the PubMed, Web of Science, Excerpta Medica database (Embase), China National Knowledge Infrastructure (CNKI), Wanfang, preprinted bioRxiv and medRxiv databases for documents and guidelines from earliest available date up until October 3rd, 2020. We obtained the latest information about COVID-19 and influenza and summarized and compared their biological characteristics, epidemiology, clinical manifestations, pathological mechanisms, treatments, and prognostic factors. We show that although COVID-19 and influenza are different in many ways, there are numerous similarities; thus, in addition to using nucleic acid-based polymerase chain reaction (PCR) and antibody-based approaches, clinicians and epidemiologists should distinguish between the two using their respective characteristics in early stages. We should utilize experiences from other epidemics to provide additional guidance for the treatment and prevention of COVID-19.
\end{abstract}

Key words: Coronavirus disease 2019 (COVID-19); Influenza; Severe acute respiratory syndrome coronavirus 2 (SARS-CoV-2)

\section{Introduction}

Coronavirus disease 2019 (COVID-19) was first identified at the end of 2019. The Chinese Center for Disease Control and Prevention (China CDC) assessed initial patients and identified a novel coronavirus, which was later named 2019 novel coronavirus (2019-nCoV). Later, on February 11th, 2020, the World Health Organization (WHO) officially named this disease COVID-19, while the International Virus Classification Committee identified the pathogen as severe acute respiratory syndrome coronavirus 2 (SARS-CoV-2) (Tan WJ et al., 2020). COVID-19 poses a threat to global public health and is a challenge to the whole people, government, and society (Shi et al., 2020).

\footnotetext{
$\triangle$ Xiaonan TAO, taoxn2004@163.com

(iD) Yu BAI, https://orcid.org/0000-0002-0253-4853

Received Aug. 17, 2020; Revision accepted Oct. 12, 2020; Crosschecked Jan. 6, 2021
}

(C) Zhejiang University Press 2021
The outbreak of COVID-19 began in December 2019, corresponding to the influenza season. It is important for clinicians to distinguish COVID-19 from other respiratory infections, including influenza. One study showed that the global number of respiratory influenza-related deaths was between 290000 and 650000 per year (Iuliano et al., 2018), while another study showed that the global number of deaths from lower respiratory tract infections directly caused by influenza was between 99000 and 200000 per year (GBD 2017 Influenza Collaborators, 2019). The WHO estimates that the annual influenza pandemic infects approximately 1000000000 people worldwide, with critical cases between 3000000 and 5000000 and deaths between 300000 and 500000 (Krammer et al., 2018). In the early days of COVID-19, it was difficult to differentiate influenza from COVID-19 because of lack of experience; however, as treatment regimens and prognoses of COVID-19 and influenza are different, it is very important for clinicians and epidemiologists to accurately differentiate the two respiratory infections on the basis of their respective 
characteristics in early stages. In order to differentiate between the two, we should also note the possibility of coinfection with both diseases simultaneously.

We reviewed official documents and news released by the National Health Commission of the People's Republic of China, the China CDC, the United States CDC, and the WHO, and we also searched the PubMed, Web of Science, Embase, China National Knowledge Infrastructure (CNKI), Wanfang, preprint bioRxiv and medRxiv databases for literature and guidelines from the earliest available date up until October 3rd, 2020. The biological characteristics, epidemiology, clinical manifestations, pathological mechanisms, treatments, and prognostic factors of COVID-19 and influenza are therefore summarized and compared (Tables 1 and 2).

\section{Virology and epidemiology}

Coronaviruses can cause multisystem infection in numerous animals; in humans, these viruses mainly cause respiratory tract infection (Drosten et al., 2003; Zaki et al., 2012; Yin and Wunderink, 2018). SARS$\mathrm{CoV}-2$, however, is a new strain that has not been identified before in humans; this is the 7th known human coronavirus and is similar to other pathogenic coronaviruses, including SARS-CoV and Middle East respiratory syndrome coronavirus (MERS-CoV) (Munster et al., 2020). Data show that SARS-CoV-2 is an RNA virus with a diameter between 60 and $140 \mathrm{~nm}$ (Zhu N et al., 2020). A total of 16 clavicular glycoprotein peaks in the envelope form the virus crown or corona (Xu XT et al., 2020). Subsequent to the discovery of SARS-CoV-2 by the China CDC,

Table 1 Differences in virology and epidemiology between SARS-CoV-2 and influenza viruses

\begin{tabular}{lllccc}
\hline \multicolumn{1}{c}{ Virus } & Natural hosts & \multicolumn{1}{c}{ Infection mechanism } & Type & $R_{0}$ & Incubation period (d) \\
\hline SARS-CoV-2 & Bats & $\begin{array}{c}\text { S protein interaction with human ACE2 } \\
\text { receptors }\end{array}$ & RNA & $1.40-6.49$ & Average 4-6 \\
$\begin{array}{l}\text { Influenza } \\
\text { viruses }\end{array}$ & $\begin{array}{c}\text { Poultry, } \\
\text { wild birds }\end{array}$ & $\begin{array}{c}\text { Respiratory epithelium is the only site for } \\
\text { effective cleavage of HA molecules }\end{array}$ & RNA & $1.30-1.71$ & Average 2 \\
\hline
\end{tabular}

SARS-CoV-2: severe acute respiratory syndrome coronavirus 2 ; ACE2: angiotensin converting enzyme 2; HA: hemagglutinin; $R_{0}$ : average number of additional individuals infected during the course of an infection case.

Table 2 Differences in the clinical characteristics between COVID-19 and influenza

\begin{tabular}{|c|c|c|c|c|}
\hline Disease & Mortality (\%) & Median age (year) & Sex & Respiratory symptom \\
\hline COVID-19 & $1.40-3.67$ & $44-56$ & Male biased & $\begin{array}{l}\text { Similar to the common cold in early stages; } \\
\text { nonproductive cough and shortness of } \\
\text { breath are relatively large }\end{array}$ \\
\hline Influenza & $0.13-1.36$ & $\begin{array}{l}\text { H7N9: 62; H5N1: 26; } \\
\text { and 2009-H1N1: } 25\end{array}$ & Male biased & Cough is the common symptom \\
\hline Disease & \multicolumn{2}{|c|}{ Other symptom } & Hematology & Pulmonary CT \\
\hline COVID-19 & \multicolumn{2}{|c|}{$\begin{array}{l}\text { Fever, chemical sensory disturbance, } \\
\text { damage to the reproductive system, } \\
\text { constitutional symptoms and rash }\end{array}$} & $\begin{array}{l}\text { Lymphocytopenia is } \\
\text { predominant }\end{array}$ & $\begin{array}{l}\text { Ground-glass opacity mostly located in the } \\
\text { periphery and involved the lower lobe }\end{array}$ \\
\hline Influenza & \multicolumn{2}{|c|}{ High fever and eye symptoms } & $\begin{array}{l}\text { Lymphocytopenia is } \\
\text { predominant }\end{array}$ & $\begin{array}{l}\text { Shadows tend to present centrally, } \\
\text { peripherally, or randomly, often involving } \\
\text { the five lobes and mediastinal emphysema } \\
\text { and pneumothorax were reported }\end{array}$ \\
\hline Disease & \multicolumn{2}{|c|}{ Pathological manifestations } & Treatment & Prognostic factors of a poor outcome \\
\hline COVID-19 & \multicolumn{2}{|c|}{$\begin{array}{l}\text { More exudative lesions, less fibrosis, } \\
\text { and consolidation }\end{array}$} & $\begin{array}{l}\text { Current empirical and } \\
\text { symptomatic treatment }\end{array}$ & Old age, obesity, and comorbidities \\
\hline Influenza & \multicolumn{2}{|c|}{$\begin{array}{l}\text { Pulmonary fibrosis, thrombosis, } \\
\text { and hemorrhage }\end{array}$} & $\begin{array}{l}\text { Vaccination and } \\
\text { antiviral therapy }\end{array}$ & $\begin{array}{l}\text { Younger age, old age, pregnancy, and } \\
\text { postpartum status, obesity, as well as } \\
\text { comorbidities and low immunity }\end{array}$ \\
\hline
\end{tabular}

COVID-19: coronavirus disease 2019; CT: computed tomography. 
virus sequence alignment analysis led to the speculation that the natural host of this virus may be bats; indeed, as SARS-CoV-2 can infect human respiratory epithelial cells through interactions between $\mathrm{S}$ proteins and the human angiotensin converting enzyme 2 (ACE2) receptor complex, this virus has a strong ability to infect humans (Huang et al., 2020). In contrast, influenza is an acute respiratory infectious disease caused by its own virus. Similar to SARS-CoV-2, influenza has high infectivity characteristics, high incidence, rapid onset, and easy of mutation. The influenza virus is also an RNA virus; the structure of this virus can be divided into three parts: the envelope, matrix proteins, and the core. Thus, according to antigenic variations in the nucleoprotein and matrix protein, influenza viruses are divided into four types: influenza A, B, C, and D. Influenza A, B, and C can infect humans, while influenza $\mathrm{C}$ is rare and usually causes only mild upper respiratory diseases (World Health Organization, 2014). Similar to SARS-CoV-2, human influenza viruses mainly replicate in the respiratory tract epithelium, initiating the production of viral proteins. Viral replication efficiency varies depending on cell type, while in humans, the respiratory epithelium is the only site where hemagglutinin (HA) molecules effectively cleave and produce infectious virus particles (Webster et al., 2013). Poultry and wild birds are the main hosts of influenza virus (Hill et al., 2019), while ferrets have traditionally been used as models for transmission because most human influenza viruses do not require any adaptation to infect and spread among these mammals. Thus, studies on ferrets have shown that the soft palate is rich in $\alpha 2,6$-linked sialic acid, the first choice for HA protein binding in human influenza viruses (Nicholls et al., 2007; Lakdawala et al., 2015).

Values of $R_{0}$ indicate the average number of additional individuals infected during the course of an infection case. Data show that estimates for the SARSCoV-2 $R_{0}$ range between 1.40 and 6.49 people, with an average of 3.28 people and a median of 2.79 people (Tolksdorf et al., 2020). As a comparison, the number of influenza outbreaks in Thai prisons is increasing every year; Suphanchaimat et al. (2020) analyzed 375763 prisoners in Thailand and found that the influenza $R_{0}$ was 1.40 , while another study reported that estimated $R_{0}$ during the 2009 influenza H1N1 outbreak in Mexico was between 1.30 and
1.71 people (Yang et al., 2009). These data show that the transmission rate of SARS-CoV-2 is higher than that of seasonal influenza (Liu Y et al., 2020).

The incubation period of COVID-19 ranges up to $24 \mathrm{~d}$ (Wang YX et al., 2020), but is generally between 4 and $6 \mathrm{~d}$. One recent study conducted by Guan et al. (2020) showed that the median incubation period for COVID-19 is $4 \mathrm{~d}$, while Zhang et al. (2020) estimated the average incubation period to be $5.2 \mathrm{~d}$. The incubation period of influenza ranges between 1 and $7 \mathrm{~d}$ (Sihler and Park, 2011), but is generally $2 \mathrm{~d}$ (Kalarikkal and Jaishankar, 2020).

Data from different studies vary regarding the mortality rate. In the early phase of the coronavirus epidemic, the mortality rate in Wuhan was between 4.3\% and $14.3 \%$ (Huang et al., 2020; Wang DW et al., 2020). As this was the beginning of the epidemic, the early mortality rate in Wuhan was undoubtedly high. Subsequently, studies in China and other countries around the world indicated a mortality rate of between approximately $1.40 \%$ and $3.67 \%$ (Guan et al., 2020; Verity et al., 2020). Indeed, as of October 3rd, 2020, the world has confirmed 34776389 with 1029049 deaths and a mortality rate of approximately $2.9 \%$. In the United States, the CDC estimates that since 2010 , the influenza mortality rate is between approximately $0.13 \%$ and $1.36 \%$ (Centers of Disease Control and Prevention, 2020); the mortality rate of influenza is therefore much lower than that of COVID-19. The immediate cause of death from influenza is subsequent pneumonia, while the mortality rate is $6.8 \%$ in the case of influenza-induced pneumonia (Centers of Disease Control and Prevention, 2020). The COVID-19 pandemic is still ongoing and so a final mortality rate still needs to be counted.

\section{Clinical manifestations}

\subsection{Age and sex}

Although data show that COVID-19 patients range in age from one month old to 94 years old, adults are relatively more susceptible than children. The median age found by different studies was also different; most patients were between 44 and 56 years old and the proportion of male patients was slightly higher than that of female patients (Chen et al., 2020; Guan et al., 2020; Wang DW et al., 2020; 
Zhang et al., 2020). The sex ratio (male: female) was 1.3:1.0 (Li Q et al., 2020). X chromosomes and sex hormones play an important role in innate and adaptive immunities (Jaillon et al., 2019). As the epidemic has progressed, the proportions of infected young and elderly (age of $>64$ years) individuals have also increased. It remains the case that most critically ill patients are older; Yang et al. (2020) analyzed data from 52 patients with COVID-19 who were hospitalized in the intensive care unit (ICU) of Jinyintan Hospital, Wuhan, China between late December 2019 and January 26th, 2020. The average age of the critically ill patients was 59.7 years and $67 \%$ of the critically ill patients were male.

In contrast, individuals affected by influenza tend to be younger than those affected by COVID-19; children less than 14 years old are more susceptible to influenza than COVID-19. In similar work, Cao et al. (2009) analyzed data from 426 people infected with the 2009 pandemic influenza virus from 61 hospitals across 20 provinces of China between May 2009 and June 2009. The results of this study showed that the average age of these 426 patients was 23.4 years and $53.8 \%$ of them were male. The median age of people infected with different influenza virus types is also different; for example, the median age of people infected with H7N9 was 62 years, while the median ages of people infected with H5N1 and $2009 \mathrm{H} 1 \mathrm{~N} 1$ were 26 and 25 years, respectively (Cowling et al., 2013). Amongst seasonal influenza and 2009 pandemic influenza patients, the hospitalization rate for elderly ( $\geqslant 85$ years old) individuals was highest (Moa et al., 2020), and $30 \%-40 \%$ of confirmed influenza inpatients are diagnosed with acute pneumonia. These pneumonia patients are more likely to be young ( $<5$ years old), elderly ( $>65$ years old), Caucasian, nursing home residents, smokers, immunocompromised, or to have a history of chronic lung or heart disease (Kalil and Thomas, 2019).

\subsection{Symptoms}

Data show that COVID-19-infected people generally show mild symptoms of upper respiratory tract infection similar to the common cold in early stages (Chan et al., 2019). The bulk of cases exhibiting mild (81\%) symptoms are usually self-limiting and patients generally recover within two weeks (Wu and McGoogan, 2020). In contrast, severe cases progress rapidly, resulting in acute respiratory distress syndrome (ARDS) and septic shock which eventually leads to multiple organ failure. Some comprehensive studies found that the most common symptoms include fever, occurring in between $88.0 \%$ and $98.6 \%$ of the total number of cases (Chen et al., 2020; Guan et al., 2020; Wang DW et al., 2020). In contrast, Guan et al. (2020) found that the proportion of patients with fever was not the same at admission (43.8\%) as it was during hospitalization (88.7\%). A range of other symptoms include dry cough, fatigue, and shortness of breath, occurring in between $60 \%$ and $70 \%$ of cases. Symptoms such as muscle soreness, delirium, headache, sore throat, congestion, chest pain, diarrhea, nausea, and vomiting remain relatively rare, occurring in between approximately $1 \%$ and $11 \%$ of cases (Chen et al., 2020; Guan et al., 2020; Wang DW et al., 2020). A study has shown that, compared with influenza, chemosensory dysfunction is closely related to COVID-19 infection (Yan et al., 2020). In another study, Tang et al. (2020) found that compared with H1N1 patients, COVID-19 patients are more likely to develop nonproductive coughs accompanied by obvious constitutional symptoms, such as fatigue and gastrointestinal symptoms. One recent study suggested that COVID-19 is a systemic disease that can cause multisystem lesions (Tersalvi et al., 2020). Potential hypogonadism and attention should be paid to the effects of SARS-CoV-2 on the reproductive system (Fan et al., 2020; Ma et al., 2020). Skin is one of the target organs affected by COVID-19 infection, and a total of 5.3\% of patients developed a rash before they developed any symptoms (Li HX et al., 2020).

Influenza can also be characterized by a variety of systemic symptoms including high fever, chills, headache, myalgia, discomfort, and anorexia as well as respiratory symptoms including cough, congestion, and sore throat. The most common symptoms are high fever and cough, occurring in $60 \%-80 \%$ of cases. Diarrhea is relatively rare, occurring in approximately $2.8 \%$ of cases (Cao et al., 2009); fever is the most important and common symptom in influenza where body temperature potentially reaches $41^{\circ} \mathrm{C}$ within the first 24 h (Nicholson, 1992; Cox and Subbarao, 1999; Cao et al., 2009; Long et al., 2012; Bennett et al., 2015). Influenza tends to cause hyperthermia and can also manifest as eye symptoms, including photophobia, conjunctivitis, tearing, and eye movement pain. 


\subsection{Hematological indicators}

Lymphocytopenia is common in patients with COVID-19. This occurs in more than $70 \%$ of cases and indicates that immune cell consumption and cellular immune function are both impaired. An increase in C-reactive protein occurs in approximately $50 \%$ of cases. Coagulation disorders such as thrombocytopenia and prolonged prothrombin time occur in between approximately $30 \%$ and $58 \%$ of cases, and increases in lactate dehydrogenase and leukopenia can also occur. Increases in alanine aminotransferase, aspartate aminotransferase, and D-dimer levels are uncommon (Guan et al., 2020; Wang DW et al., 2020). There were many differences in laboratory results between patients admitted to the ICU and patients who are not; indeed, patients admitted to the ICU had higher white blood cell and neutrophil counts and higher D-dimer, creatine kinase, and creatine levels than those not admitted to the ICU (Chen et al., 2020). In recent work, Huang et al. (2020) also found that the plasma levels of interleukin-2 (IL-2), IL-7, IL-10, granulocyte colony-stimulating factor (GCSF), interferoninducible protein-10 (IP-10), monocyte chemotactic protein-1 (MCP-1), macrophage inflammatory protein 1A (MIP1A), and tumor necrosis facto- $\alpha$ (TNF- $\alpha$ ) in ICU patients were higher than those in non-ICU patients. In non-survivors, neutrophil counts and D-dimer, blood urea, and creatinine levels continued to increase until death while lymphocyte counts continued to decrease until death.

The hematological parameters of influenza and COVID-19 are similar. A study of influenza patients with normal or reduced white blood cell counts by Han et al. (2020) showed that the platelet (PLT) counts in influenza virus-positive patients were significantly lower than those in influenza virus-negative patients. Those infected with the influenza virus recovered and PLTs returned to normal levels. The sensitivity of the neutrophil/lymphocyte ratio is high and so an increase in the neutrophil/lymphocyte ratio is a good diagnostic tool for screening patients with influenza virus infection. The 2009 pandemic H1N1 study found that half of the patients had an abnormal CD4:CD8 ratio (Cao et al., 2009).

\subsection{Pulmonary CT}

Imaging findings from COVID-19 patients revealed ground-glass shadows, the most common imaging manifestation on chest computed tomography (CT) which was seen in more than $56.4 \%$ of patients. Around $17.9 \%$ of non-critically ill patients had no imaging abnormalities, while $2.9 \%$ of critically ill patients had no imaging abnormalities (Guan et al., 2020). Thus, after two weeks of progression, lesions were gradually absorbed, revealing extensive opacities and subpleural parenchymal bands on images of recovered patients (Xie and Chen, 2020). It is the case that compared with those of patients with influenza, the imaging findings of patients with COVID-19 are more likely to reveal ground-glass opacity, while patients with influenza tend to have localized patchy shadows (Cao et al., 2009). In another study, Onigbinde et al. (2020) analyzed chest $\mathrm{CT}$ findings by selecting 17 original studies on COVID-19 and influenza. Differences show that COVID-19 ground-glass opacities are usually peripherally located with the lower lobes being commonly involved while influenza has a central, peripheral, or random distribution usually affecting the five lobes. Vascular engorgement, pleural thickening, and subpleural lines are reported in COVID-19 patients while pneumomediastinum and pneumothorax have only been reported in influenza cases. The chest CT performances of COVID-19 and influenza overlap but have their own characteristics.

\section{Pathological mechanisms}

SARS-CoV-2 infection may be related to cellular immune deficiency, coagulation activation, cardiomyocyte injury, liver injury, and kidney injury. Neutropenia might be related to cytokine storms caused by virus invasion, while coagulation activation may be related to persistent inflammatory responses. Acute renal injury may also be related to the direct action of viruses, hypoxia, and shock. Three pathological mechanisms might be associated with death in patients (Wang DW et al., 2020); some patients progressed rapidly, developed ARDS and septic shock, and eventually experienced multiple organ failure (Chen et al., 2020). In another recent study, Tian et al. (2020) examined the lungs of two patients with lung adenocarcinoma concomitant with early COVID-19. In addition to tumors, edemas, protein exudation, focal pulmonary cell reactive hyperplasia, patchy inflammatory cell infiltrations, and multinucleated giant cells in lung 
tissue were present in both patients. As neither of these patients showed symptoms of pneumonia during their operations, hyaline membranes were not obvious. These changes may represent the early stage of COVID-19 pulmonary pathology. One autopsy study carried out by $\mathrm{Xu} \mathrm{Z}$ et al. (2020) showed the presence of exudative lesions as well as lower fibrosis and consolidation in patients with COVID-19. A microscopic bilateral diffuse alveolar injury with fibromyxoid exudation was observed, which suggests ARDS. Interstitial mononuclear inflammatory infiltrates were dominated by lymphocytes, while enlarged multinucleated syncytial cells in the lungs showed viral-related cytopathic changes, and there were no obvious virus inclusion bodies in the nuclei or cytoplasm. The results of flow cytometry analysis showed that the numbers of CD4 and CD8 T cells in peripheral blood decreased significantly, and these remained in a highly activated state. This suggests that severe damage in the late stages of COVID-19 is immune-related rather than virus-related.

Pulmonary fibrosis, thrombus, and bleeding are more common in influenza than in COVID-19 patients. Autopsies conducted on influenza patients show necrotizing bronchitis, hyaline membranes, intra-alveolar hemorrhage, edema, and interstitial fibrosis. Zeng et al. (2015) performed a percutaneous lung biopsy in patients with late-stage avian influenza. Histopathological changes in these patients were mainly fibrotic in nature; some alveolar epithelial necrosis and exfoliation as well as reactive proliferation of alveolar epithelium were observed, although no viral inclusion bodies were present in epithelial cells. Serous cellulose, red blood cells, neutrophils, hyaline membranes, squamous metaplasia, and tissue exudate were observed in the alveolar cavity. Indeed, some alveoli showed atrophy or compensatory emphysema, while pulmonary interstitial fibrosis, occasional white blood cells, phagocytes, and reactive blood cells were also observed. Transparent thrombus and disseminated intravascular coagulation (DIC), sometimes accompanied by vascular occlusion, were also seen in pulmonary interstitial capillaries.

\section{Treatments}

Empirical and symptomatic treatments can be administered in early COVID-19 phases. However, in cases where secondary bacterial or fungal infection occurs, drugs should be used on the basis of culture and sensitivity testing results. Commonly administered antibiotics include cephalosporins, quinolones, carbapenems, tetracyclines, linezolid, and antifungal agents. The duration of antibiotic treatment is generally between 3 and $17 \mathrm{~d}$, and the drugs commonly used in early clinical settings are oseltamivir, ganciclovir, and chloroquine phosphate as well as its derivatives hydroxychloroquine, lopinavir/ritonavir, abidol, remdesivir, and Lianhuaqingwen ( $\mathrm{LH}$ ), along with appropriate amounts of glucocorticoids according to the condition of the patient even though opinions differ with regard to their efficacy. In another recent study, Tan Q et al. (2020) evaluated the antiviral effect of oseltamivir on SARS-CoV-2 via in vitro experiments and statistically evaluated whether, or not, the history of oseltamivir use has affected the progression of the disease through clinical case analysis. Oseltamivir was found to be ineffective against SARS-CoV-2 in vitro, while clinical application did not improve the symptoms and signs of patients or delay disease progression. Similarly, Liu J et al. (2020) studied 1190 laboratory-confirmed COVID-19 patients hospitalized in the Wuhan Infectious Diseases Hospital between December 29th, 2019 and February 28th, 2020. The results of this study showed that antiviral drugs, especially oseltamivir or ganciclovir, were associated with a lower risk of death in critically ill patients (odds ratio (OR) $0.17,95 \%$ confidence interval $(\mathrm{CI}) 0.05-0.64, P<0.001)$. In another study, Yousefi et al. (2020) came to a different conclusion: this research showed that oseltamivir is ineffective in the management of COVID-19 and so is not currently recommended. Oseltamivir clinical trials, such as national clinical trial (NCT) number NCT04255017, are actively being carried out around the world and we await further results (Oroojalian et al., 2020). Chloroquine phosphate and its derivative hydroxychloroquine are subject to clinical studies. In one example, Ayerbe et al. (2020) summarized clinical data from 2075 COVID-19 patients admitted to 17 hospitals in Spain between March 1st, 2020, and April 20th, 2020; these results show that hydroxychloroquine is associated with lower mortality (OR $0.44,95 \%$ CI $0.29-0.67)$. In contrast, in another observational study of hydroxychloroquine conducted on 1376 patients in a large medical center in New York City, the United States, hydroxychloroquine (600 mg twice a day (BID) on Day 1, followed by $400 \mathrm{mg}$ once daily (QD) for a median of $5 \mathrm{~d}$ ) was 
given to 811 patients. Results show that, of these patients, intubation or death occurred in $25.1 \%$, indicating that the administration of this drug did not increase risk or benefit (Geleris et al., 2020). As a result, on March 28th, 2020, the United States Food and Drug Administration (FDA) announced that COVID-19hospitalized patients can urgently be treated with chloroquine and hydroxychloroquine but this was then subsequently cancelled because recent studies have shown that these drugs do not exhibit any benefits in the treatment of COVID-19 (Lam et al., 2020). Numerous hospitals and medical institutions have launched clinical studies on chloroquine phosphate and its derivative hydroxychloroquine, which need to be concluded. One retrospective study carried out by $\mathrm{Zhu} \mathrm{Z}$ et al. (2020) showed that no viral load was detected in 16 patients taking abidol $(200 \mathrm{mg}$ three times a day (TID)), while this load in patients treated with lopinavir/ritonavir monotherapy $(400 \mathrm{mg} / 100 \mathrm{mg}$ BID) was $44.1 \%$. This suggests that abidol may be more effective than lopinavir/ritonavir for the treatment of COVID-19. A further retrospective study conducted by Lian et al. (2020) reported that the use of arbidol did enhance efficacy in non-ICU patients. A prospective multicenter study with a larger sample size is still needed to better determine the efficacy of arbidol. In similar work, Grein et al. (2020) performed clinical remdesivir trials in a group of patients hospitalized for severe COVID-19; clinical improvements were seen in 36 (68\%) of the 53 patients and further randomized controlled trials are needed to verify these results. Data show that LH significantly inhibited the replication of SARS-CoV-2 in Vero E6 cells and significantly reduced the production of proinflammatory cytokines (TNF- $\alpha$, IL-6, C-C motif chemokine ligand 2 (CCL-2)/MCP-1 and C-X-C motif chemokine ligand 10 (CXCL-10)/IP-10) at the gene level. It is clear that $\mathrm{LH}$ can cause abnormal virion morphologies in cells. These findings suggest that $\mathrm{LH}$ can prevent virus attacks, making this a potential new therapy for the control of COVID-19 (Li RF et al., 2020). Current interim guidelines published by the WHO do not support the use of systemic corticosteroids in the treatment of viral pneumonia and ARDS in suspected COVID-19 patients. The results of a hormone therapy study for COVID-19 published online in the New England Journal of Medicine on July 17th, 2020, showed that among hospitalized patients, the use of dexamethasone reduced 28-d mortality in patients who were randomly treated with invasive mechanical ventilation or oxygen alone. No significant differences in mortality between the hormone group and the control group were seen in patients without respiratory support. This study showed that hormone therapy is not required for mild COVID-19 patients, while hormone use can reduce 28 -d mortality in severely affected patients. This study only observed mortality rate over $28 \mathrm{~d}$ and so the results of further long-term mortality observations need to be presented (The RECOVERY Collaborative Group, 2020). Passive antibody injection through convalescent plasma infusion may provide immediate short-term immunity in susceptible individuals (Bloch et al., 2020), and traditional Chinese medicine, oxygen therapy, mechanical ventilation, and extracorporeal membrane oxygenation (ECMO) can also be initiated according to patient condition and symptoms. Scientists around the world have attempted to develop a vaccine as a preventive measure (Xie and Chen, 2020) but, to date, no drugs have been targeted for SARS-CoV-2.

The most effective way to prevent and control influenza is vaccination and antiviral treatment. Many countries recommended that individuals six months and older receive influenza vaccination once a year (Isenor et al., 2018; Carlson et al., 2019). However, due to antigenic variations in the influenza virus and individual differences in host immunity, the immune effect may be poor. Timely antiviral therapy is particularly important for diagnosed patients $(\mathrm{Qu}$ et al., 2015) with one major class of antiviral drugs being neuraminidase inhibitors (NAIs) which include old NAIs, such as oseltamivir and zanamivir, as well as new ones, for example laninamivir and peramivir. Another major class of antiviral drugs is M2 ion channel protein inhibitors (M2 inhibitors) which include amantadine, while others include HA inhibitors, such as entry-blocker (EB) peptides and arbidol, virus RNA polymerase inhibitors, such as ribavirin, and traditional Chinese medicines, which exhibit anti-infective activity (Li et al., 2018). As a result of high drug resistance, M2 inhibitors have been withdrawn from the market. A range of drugs have been shown to be effective against H1N1 in the past, but most viral strains have developed resistance. At present, oseltamivir resistance is rare while zanamivir resistance is extremely rare (Lampejo, 2020). NAIs are currently included in national and international guidelines for the use of 
influenza drugs to guide clinical treatment (Harper et al., 2009; Committee on Infectious Diseases, 2014). Corticosteroid therapy does not significantly improve the survival rate of patients infected with influenza A virus and may even be associated with an increased mortality rate (Brun-Buisson et al., 2011). Targeted host inflammation has therefore also become the focus of new treatments. One study used the wellcharacterized mammalian target of rapamycin (mTOR) inhibitor rapamycin/sirolimus to inhibit inflammation, thereby improving results due to decreased inflammatory activity (Wang et al., 2014; Jia et al., 2018). Plasma immunotherapy and other symptomatic therapies can be administered according to patient condition.

\section{Factors associated with poor prognosis}

COVID-19 patients are most often transferred to the ICU because of ARDS, arrhythmia, and shock. In one study, Wang BL et al. (2020) conducted a meta-analysis of 1558 COVID-19 patients from six studies. This meta-analysis showed no correlation between an increased risk of COVID-19 and liver disease, malignant tumors, or kidney disease. Hypertension, diabetes, chronic obstructive pulmonary disease (COPD), cardiovascular disease, and cerebrovascular disease have been shown to be the main risk factors for COVID-19, while old age, obesity, and comorbidities may be related to an increase in mortality and are predictors of a poor prognosis in patients (Chen et al., 2020; Guan et al., 2020; Wang DW et al., 2020; Zhang et al., 2020).

Influenza patients are most commonly transferred to the ICU due to ARDS, septicemia, and secondary severe bacterial infection. Diseases such as myocarditis, pericarditis, and central nervous system diseases are rare. The immediate cause of death from influenza is usually subsequent pneumonia (Grant et al., 2020); prognostic factors in influenza patients tend to be younger age and pregnancy but these are not prognostic factors for COVID-19 patients. Rowe et al. (2014) showed that influenza can cause significantly increased morbidity and mortality in young children, elderly individuals, pregnant and postpartum women, and patients with diseases and low immune function. American Indians and Alaskan Natives are also highly likely to suffer from severe influenza complications (Doxey et al., 2019). European surveillance has shown that among patients diagnosed with influenza, independent risk factors associated with ARDS were ages between 36 and 55 years, pregnancy, and obesity, while protective factors associated with ARDS include female sex and influenza vaccination. It is worth noting that the only factors significantly associated with death were increased severity scores and ages older than 55 years (Bonmarin et al., 2015).

\section{Conclusions}

Although COVID-19 and influenza differ in many ways, there are also many similarities and so clinicians and epidemiologists should differentiate between them as early as possible. Indeed, both SARS$\mathrm{CoV}-2$ and influenza viruses have high infectivity characteristics, a high incidence, rapid onset, and easy of mutation. The transmission rate of SARS$\mathrm{CoV}-2$ is higher than that of seasonal influenza, while the mortality rate of the latter is much lower than that of COVID-19. Influenza tends to affect younger patients than COVID-19; indeed, children under 14 years old are more susceptible to influenza than to COVID-19. Data show that compared with those with influenza, chemosensory dysfunction, rash, and damage to the reproductive system are more common in those with COVID-19 infection, and these patients are more likely to develop non-productive coughs with obvious constitutional symptoms than influenza patients. Influenza patients tend to have a high fever more frequently than COVID-19 patients. In terms of imaging findings, ground-glass opacity was mostly located in the periphery and involved the lower lobe in COVID-19 patients, while a shadow in influenza patients tended to present central, peripherally, or randomly, often involving the five lobes. Mediastinal emphysema and pneumothorax were only reported in influenza studies. Pathologically, pulmonary fibrosis, thrombus, and bleeding are more common in influenza patients than in COVID-19 patients. The prognostic factors of influenza patients tend to be young age and pregnancy but these are not prognostic factors in COVID-19 patients, while obesity, comorbidities, and old age are associated with increased mortality in these patients.

In addition to differences between COVID-19 and influenza in early diagnosis, we also draw attention to 
the following points: the first symptoms of COVID19 are enhanced compared to influenza symptoms, in addition to respiratory symptoms such as cough and dyspnea. The bulk of patients with COVID-19 also experience fatigue, myalgia, headache, digestive tract, and other symptoms. The hematology of the two diseases is also similar but the odds of increased creatine kinase in COVID-19 are higher while elevated $\mathrm{C}$ reactive protein is a more common phenomenon in these patients. CT images for COVID-19 are more diverse and include consolidation, crazy paving patterns, rounded opacities, air bronchograms, tree-in-bud sign, interlobular septal thickening, and bronchiolar wall thickening. COVID-19 develops faster than influenza pneumonia and is both progressive and absorbed. Differentiating between the two, it is also important to note the possibility of coinfection with both diseases at the same time.

COVID-19 control remains a challenging task and we should utilize our experiences from other epidemics to provide additional guidance for the early diagnosis, treatment, and prevention of this virus.

\section{Author contributions}

$\mathrm{Yu}$ BAI analyzed the literature and prepared the first draft of the manuscript. Yu BAI and Xiaonan TAO revised, edited, and checked the final version. Both authors have read and approved the final manuscript.

\section{Compliance with ethics guidelines}

Yu BAI and Xiaonan TAO declare that they have no conflict of interest.

This article does not contain any studies with human or animal subjects performed by either of the authors.

\section{References}

Ayerbe L, Risco-Risco C, Ayis S, 2020. The association of treatment with hydroxychloroquine and hospital mortality in COVID-19 patients. Intern Emerg Med, 15(8):1501-1506. https://doi.org/10.1007/s11739-020-02505-x

Bennett JE, Dolin R, Blaser MJ, 2015. Mandell, Douglas, and Bennett's Principles and Practice of Infectious Diseases, 8th Ed. Elsevier, Philadelphia, USA. https://doi.org/10.1016/C2012-1-00075-6

Bloch EM, Shoham S, Casadevall A, et al., 2020. Deployment of convalescent plasma for the prevention and treatment of COVID-19. J Clin Invest, 130(6):2757-2765. https://doi.org/10.1172/JCI138745

Bonmarin I, Belchior E, Bergounioux J, et al., 2015. Intensive care unit surveillance of influenza infection in France: the 2009/10 pandemic and the three subsequent seasons. Euro Surveill, 20(46):30066.
https://doi.org/10.2807/1560-7917.ES.2015.20.46.30066

Brun-Buisson C, Richard JCM, Mercat A, et al., 2011. Early corticosteroids in severe influenza $\mathrm{A} / \mathrm{H} 1 \mathrm{~N} 1$ pneumonia and acute respiratory distress syndrome. Am J Respir Crit Care Med, 183(9):1200-1206. https://doi.org/10.1164/rccm.201101-0135OC

Cao B, Li XW, Mao Y, et al., 2009. Clinical features of the initial cases of 2009 pandemic influenza A (H1N1) virus infection in China. N Engl J Med, 361(26):2507-2517. https://doi.org/10.1056/NEJMoa0906612

Carlson SJ, Scanlan C, Marshall HS, et al., 2019. Attitudes about and access to influenza vaccination experienced by parents of children hospitalised for influenza in Australia. Vaccine, 37(40):5994-6001. https://doi.org/10.1016/j.vaccine.2019.08.021

Centers of Disease Control and Prevention, 2020. Weekly U.S. Influenza Surveillance Report. https://www.cdc. gov/flu/ weekly/index.htm

Chan KW, Wong VT, Tang SCW, 2019. COVID-19: an update on the epidemiological, clinical, preventive and therapeutic evidence and guidelines of integrative Chinese-Western medicine for the management of 2019 novel coronavirus disease. Am J Chin Med, 48(3):737-762. https://doi.org/10.1142/S0192415X20500378

Chen NS, Zhou M, Dong X, et al., 2020. Epidemiological and clinical characteristics of 99 cases of 2019 novel coronavirus pneumonia in Wuhan, China: a descriptive study. Lancet, 395(10223):507-513. https://doi.org/10.1016/S0140-6736(20)30211-7

Committee on Infectious Diseases, 2014. Recommendations for prevention and control of influenza in children, 20142015. Pediatrics, 134(5):e1503-e1519. https://doi.org/10.1542/peds.2014-2413

Cowling BJ, Jin LM, Lau EHY, et al., 2013. Comparative epidemiology of human infections with avian influenza A H7N9 and H5N1 viruses in China: a population-based study of laboratory-confirmed cases. Lancet, 382(9887): 129-137. https://doi.org/10.1016/S0140-6736(13)61171-X

Cox NJ, Subbarao K, 1999. Influenza. Lancet, 354(9186): 1277-1282. https://doi.org/10.1016/S0140-6736(99)01241-6

Doxey M, Chrzaszcz L, Dominguez A, et al., 2019. A forgotten danger: burden of influenza mortality among American Indians and Alaska natives, 1999-2016. J Public Health Manag Pract, 25(Suppl 5):S7-S10. https://doi.org/10.1097/PHH.0000000000001062

Drosten C, Günther S, Preiser W, et al., 2003. Identification of a novel coronavirus in patients with severe acute respiratory syndrome. $N$ Engl J Med, 348(20):1967-1976. https://doi.org/10.1056/NEJMoa030747

Fan CB, Li K, Ding YH, et al., 2020. ACE2 expression in kidney and testis may cause kidney and testis damage after 2019-nCoV infection. medRxiv, preprint. https://doi.org/10.1101/2020.02.12.20022418

GBD 2017 Influenza Collaborators, 2019. Mortality, morbidity, and hospitalisations due to influenza lower respiratory 
tract infections, 2017: an analysis for the Global Burden of Disease Study 2017. Lancet Respir Med, 7(1):69-89. https://doi.org/10.1016/S2213-2600(18)30496-X

Geleris J, Sun YF, Platt J, 2020. Observational study of hydroxychloroquine in hospitalized patients with COVID-19. N Engl J Med, 382(25):2411-2418. https://doi.org/10.1056/NEJMoa2012410

Grant WB, Lahore H, McDonnell SL, et al., 2020. Evidence that vitamin D supplementation could reduce risk of influenza and COVID-19 infections and deaths. Nutrients, 12(4):988.

https://doi.org/10.3390/nu12040988

Grein J, Ohmagari N, Shin D, et al., 2020. Compassionate use of remdesivir for patients with severe COVID-19. N Engl J Med, 382(24):2327-2336. https://doi.org/10.1056/NEJMoa2007016

Guan WJ, Ni ZY, Hu Y, et al., 2020. Clinical characteristics of coronavirus disease 2019 in China. N Engl J Med, 382(18): 1708-1720. https://doi.org/10.1056/NEJMoa2002032

Han QZ, Wen XM, Wang L, et al., 2020. Role of hematological parameters in the diagnosis of influenza virus infection in patients with respiratory tract infection symptoms. J Clin Lab Anal, 34(5):e23191. https://doi.org/10.1002/jcla.23191

Harper SA, Bradley JS, Englund JA, et al., 2009. Seasonal influenza in adults and children-diagnosis, treatment, chemoprophylaxis, and institutional outbreak management: clinical practice guidelines of the Infectious Diseases Society of America. Clin Infect Dis, 48(8):1003-1032. https://doi.org/10.1086/598513

Hill A, Gillings S, Berriman A, et al., 2019. Quantifying the spatial risk of avian influenza introduction into British poultry by wild birds. Sci Rep, 9:19973. https://doi.org/10.1038/s41598-019-56165-9

Huang CL, Wang YM, Li XW, et al., 2020. Clinical features of patients infected with 2019 novel coronavirus in Wuhan, China. Lancet, 395(10223):497-506. https://doi.org/10.1016/S0140-6736(20)30183-5

Isenor JE, O'Reilly BA, Bowles SK, 2018. Evaluation of the impact of immunization policies, including the addition of pharmacists as immunizers, on influenza vaccination coverage in Nova Scotia, Canada: 2006 to 2016. BMC Public Health, 18:787. https://doi.org/10.1186/s12889-018-5697-x

Iuliano AD, Roguski KM, Chang HH, et al., 2018. Estimates of global seasonal influenza-associated respiratory mortality: a modelling study. Lancet, 391(10127):1285-1300. https://doi.org/10.1016/S0140-6736(17)33293-2

Jaillon S, Berthenet K, Garlanda C, 2019. Sexual dimorphism in innate immunity. Clin Rev Allergy Immunol, 56(3):308-321. https://doi.org/10.1007/s12016-017-8648-x

Jia XH, Liu B, Bao LL, et al., 2018. Delayed oseltamivir plus sirolimus treatment attenuates H1N1 virus-induced severe lung injury correlated with repressed NLRP3 inflammasome activation and inflammatory cell infiltration. PLoS Pathog, 14(11):e1007428. https://doi.org/10.1371/journal.ppat.1007428

Kalarikkal SM, Jaishankar GB, 2020. Influenza vaccine. In: Abai $\mathrm{B}$, Abu-Ghosh $\mathrm{A}$, Acharya $\mathrm{AB}$, et al. (Eds.), StatPearls. StatPearls Publishing, Treasure Island (FL).

Kalil AC, Thomas PG, 2019. Influenza virus-related critical illness: pathophysiology and epidemiology. Crit Care, 23:258. https://doi.org/10.1186/s13054-019-2539-x

Krammer F, Smith GJD, Fouchier RAM, et al., 2018. Influenza. Nat Rev Dis Primers, 4:3. https://doi.org/10.1038/s41572-018-0002-y

Lakdawala SS, Jayaraman A, Halpin RA, et al., 2015. The soft palate is an important site of adaptation for transmissible influenza viruses. Nature, 526(7571):122-125. https://doi.org/10.1038/nature15379

Lam S, Lombardi A, Ouanounou A, 2020. COVID-19: a review of the proposed pharmacological treatments. Eur $J$ Pharmacol, 886:173451. https://doi.org/10.1016/j.ejphar.2020.173451

Lampejo T, 2020. Influenza and antiviral resistance: an overview. Eur J Clin Microbiol Infect Dis, 39(7):1201-1208. https://doi.org/10.1007/s10096-020-03840-9

Li HX, Zhao Y, Zhou L, et al., 2020. Cutaneous, skin histopathological manifestations and relationship to COVID-19 infection patients. Dermatol Ther, 33(6): e14157. https://doi.org/10.1111/dth.14157

Li Q, Guan XH, Wu P, et al., 2020. Early transmission dynamics in Wuhan, China, of novel coronavirus-infected pneumonia. N Engl J Med, 382(13):1199-1207. https://doi.org/10.1056/NEJMoa2001316

Li RF, Hou YL, Huang JC, et al., 2020. Lianhuaqingwen exerts anti-viral and anti-inflammatory activity against novel coronavirus (SARS-CoV-2). Pharmacol Res, 156: 104761. https://doi.org/10.1016/j.phrs.2020.104761

Li ZT, Li L, Zhao S, et al., 2018. Re-understanding antiinfluenza strategy: attach equal importance to antiviral and anti-inflammatory therapies. $J$ Thorac Dis, 10(S19): S2248-S2259.

https://doi.org/10.21037/jtd.2018.03.169

Lian N, Xie H, Lin S, et al., 2020. Umifenovir treatment is not associated with improved outcomes in patients with coronavirus disease 2019: a retrospective study. Clin Microbiol Infect, 26(7):917-921. https://doi.org/10.1016/j.cmi.2020.04.026

Liu J, Zhang S, Wu ZX, et al., 2020. Clinical outcomes of COVID-19 in Wuhan, China: a large cohort study. Ann Intensive Care, 10:99. https://doi.org/10.1186/s13613-020-00706-3

Liu Y, Gayle AA, Wilder-Smith A, et al., 2020. The reproductive number of COVID-19 is higher compared to SARS coronavirus. $J$ Travel Med, 27(2):taaa021. https://doi.org/10.1093/jtm/taaa021

Long SS, Pickering LK, Prober CG, 2012. Principles and Practice of Pediatric Infectious Diseases, 4th Ed. Elsevier, Edinburgh, USA. 
Ma L, Xie W, Li DY, et al., 2020. Effect of SARS-CoV-2 infection upon male gonadal function: a single centerbased study. medRxiv, preprint. https://doi.org/10.1101/2020.03.21.20037267

Moa AM, Muscatello DJ, Turner RM, et al., 2020. Estimated hospitalisations attributable to seasonal and pandemic influenza in Australia: 2001-2013. PLOS ONE, 15(4): e0230705. https://doi.org/10.1371/journal.pone.0230705

Munster VJ, Koopmans M, van Doremalen N, et al., 2020. Novel coronavirus emerging in China-key questions for impact assessment. $N$ Engl J Med, 382(8):692-694. https://doi.org/10.1056/NEJMp2000929

Nicholls JM, Bourne AJ, Chen HL, et al., 2007. Sialic acid receptor detection in the human respiratory tract: evidence for widespread distribution of potential binding sites for human and avian influenza viruses. Respir Res, 25(8):73. https://doi.org/10.1186/1465-9921-8-73

Nicholson KG, 1992. Clinical features of influenza. Semin Respir Infect, 7(1):26-37.

Onigbinde SO, Ojo AS, Fleary L, et al., 2020. Chest computed tomography findings in COVID-19 and influenza: a narrative review. BioMed Res Int, 2020: 6928368. https://doi.org/10.1155/2020/6928368

Oroojalian F, Haghbin A, Baradara B, et al., 2020. Novel insights into the treatment of SARS-CoV-2 infection: an overview of current clinical trials. Int J Biol Macromol, $165: 18-43$

https://doi.org/10.1016/j.ijbiomac.2020.09.204

Qu JX, Gu L, Pu ZH, et al., 2015. Viral etiology of community-acquired pneumonia among adolescents and adults with mild or moderate severity and its relation to age and severity. BMC Infect Dis, 15:89. https://doi.org/10.1186/s12879-015-0808-0

Rowe E, Ng PY, Chandra T, et al., 2014. Seasonal human influenza: treatment options. Curr Treat Options Infect Dis, 6(3):227-244. https://doi.org/10.1007/s40506-014-0019-z

Shi Y, Wang G, Cai XP, et al., 2020. An overview of COVID-19. $J$ Zhejiang Univ-Sci B (Biomed \& Biotechnol), 21(5): 343-360.

https://doi.org/10.1631/jzus.B2000083

Sihler KC, Park PK, 2011. Extracorporeal membrane oxygenation in the context of the 2009 H1N1 influenza A pandemic. Surg Infect, 12(2):151-158. https://doi.org/10.1089/sur.2010.082

Suphanchaimat R, Doung-Ngern P, Ploddi K, et al., 2020. Cost effectiveness and budget impact analyses of influenza vaccination for prisoners in Thailand: an application of system dynamic modelling. Int J Environ Res Public Health, 17(4):1247. https://doi.org/10.3390/ijerph17041247

Tan Q, Duan LM, Ma YL, et al., 2020. Is oseltamivir suitable for fighting against COVID-19: in silico assessment, in vitro and retrospective study. Bioorg Chem, 104:104257. https://doi.org/10.1016/j.bioorg.2020.104257
Tan WJ, Zhao X, Ma XJ, et al., 2020. A novel coronavirus genome identified in a cluster of pneumonia casesWuhan, China 2019-2020. China CDC Weekly, 2(4):61-62.

Tang X, Du RH, Wang R, et al., 2020. Comparison of hospitalized patients with ARDS caused by COVID-19 and H1N1. Chest, 158(1):195-205. https://doi.org/10.1016/j.chest.2020.03.032

Tersalvi G, Veronese G, Winterton D, 2020. Emerging evidence of myocardial injury in COVID-19: a path through the smoke. Theranostics, 10(21):9888-9889. https://doi.org/10.7150/thno.50788

The RECOVERY Collaborative Group, 2020. Dexamethasone in hospitalized patients with Covid-19- preliminary report. $N$ Engl J Med, online. https://doi.org/10.1056/NEJMoa2021436

Tian SF, Hu WD, Niu L, et al., 2020. Pulmonary pathology of early-phase 2019 novel coronavirus (COVID-19) pneumonia in two patients with lung cancer. $J$ Thorac Oncol, 15(5): 700-704. https://doi.org/10.1016/j.jtho. 2020.02.010

Tolksdorf K, Buda S, Schuler E, et al., 2020. Influenzaassociated pneumonia as reference to assess seriousness of coronavirus disease (COVID-19). Euro Surveill, 25(11): 2000258. https://doi.org/10.2807/1560-7917.ES.2020. 25.11.2000258

Verity R, Okell LC, Dorigatti I, et al., 2020. Estimates of the severity of coronavirus disease 2019: a model-based analysis. Lancet Infect Dis, 20(6):669-677. https://doi.org/10.1016/S1473-3099(20)30243-7

Wang BL, Li RB, Lu Z, et al., 2020. Does comorbidity increase the risk of patients with COVID-19: evidence from meta-analysis. Aging, 12(7):6049-6057. https://doi.org/10.18632/aging.103000

Wang CH, Chung FT, Lin SM, et al., 2014. Adjuvant treatment with a mammalian target of rapamycin inhibitor, sirolimus, and steroids improves outcomes in patients with severe H1N1 pneumonia and acute respiratory failure. Crit Care Med, 42(2):313-321. https://doi.org/10.1097/CCM.0b013e3182a2727d

Wang DW, Hu B, Hu C, et al., 2020. Clinical characteristics of 138 hospitalized patients with 2019 novel coronavirusinfected pneumonia in Wuhan, China. JAMA, 323(11): 1061-1069. https://doi.org/10.1001/jama.2020.1585

Wang YX, Wang YY, Chen Y, et al., 2020. Unique epidemiological and clinical features of the emerging 2019 novel coronavirus pneumonia (COVID-19) implicate special control measures. J Med Virol, 92(6):568-576. https://doi.org/10.1002/jmv.25748

Webster RG, Monto AS, Braciale TJ, et al., 2013. Textbook of Influenza, 2nd Ed. Wiley-Blackwell, Chichester, West Sussex, UK.

World Health Organization, 2014. Influenza (seasonal). https://www. who.int/news-room/fact-sheets/detail/influenza-(seasonal)

Wu Z, McGoogan JM, 2020. Characteristics of and important lessons from the coronavirus disease 2019 (COVID-19) outbreak in China: summary of a report of 72314 cases from the Chinese Center for Disease Control and 
Prevention. JAMA, 323(13):1239-1242.

https://doi.org/10.1001/jama.2020.2648

Xie MX, Chen Q, 2020. Insight into 2019 novel coronavirusan updated interim review and lessons from SARS-CoV and MERS-CoV. Int J Infect Dis, 94:119-124. https://doi.org/10.1016/j.ijid.2020.03.071

$\mathrm{Xu}$ XT, Chen P, Wang JF, et al., 2020. Evolution of the novel coronavirus from the ongoing Wuhan outbreak and modeling of its spike protein for risk of human transmission. Sci China Life Sci, 63(3):457-460. https://doi.org/10.1007/s11427-020-1637-5

Xu Z, Shi L, Wang YJ, et al., 2020. Pathological findings of COVID-19 associated with acute respiratory distress syndrome. Lancet Respir Med, 8(4):420-422. https://doi.org/10.1016/S2213-2600(20)30076-X

Yan CH, Faraji F, Prajapati DP, et al., 2020. Association of chemosensory dysfunction and COVID-19 in patients presenting with influenza-like symptoms. Int Forum Allergy Rhinol, 10(7):806-813.

https://doi.org/10.1002/alr.22579

Yang XB, Yu Y, Xu JQ, et al., 2020. Clinical course and outcomes of critically ill patients with SARS-CoV-2 pneumonia in Wuhan, China: a single-centered, retrospective, observational study. Lancet Respir Med, 8(5):475-481. https://doi.org/10.1016/S2213-2600(20)30079-5

Yang Y, Sugimoto JD, Halloran ME, et al., 2009. The transmissibility and control of pandemic influenza A (H1N1) virus. Science, 326(5953):729-733. https://doi.org/10.1126/science.1177373

Yin YD, Wunderink RG, 2018. MERS, SARS and other coronaviruses as causes of pneumonia. Respirology, 23(2): 130-137. https://doi.org/10.1111/resp.13196

Yousefi B, Valizadeh S, Ghaffari H, et al., 2020. A global treatments for coronaviruses including COVID-19. J Cell Physiol, 235(12):9133-9142. https://doi.org/10.1002/jcp.29785

Zaki AM, van Boheemen S, Bestebroer TM, et al., 2012. Isolation of a novel coronavirus from a man with pneumonia in Saudi Arabia. N Engl J Med, 367(19): 1814-1820. https://doi.org/10.1056/NEJMoa1211721

Zeng Z, Huang XR, Lu PX, et al., 2015. Imaging manifestations and pathological analysis of severe pneumonia caused by human infected avian influenza (H7N9). Radiol Infect Dis, 1(2):64-69. https://doi.org/10.1016/j.jrid.2015.02.003

Zhang JJ, Litvinova M, Wang W, et al., 2020. Evolving epidemiology and transmission dynamics of coronavirus disease 2019 outside Hubei province, China: a descriptive and modelling study. Lancet Infect Dis, 20(7):793-802. https://doi.org/10.1016/S1473-3099(20)30230-9

Zhu N, Zhang DY, Wang WL, et al., 2020. A novel coronavirus from patients with pneumonia in China, 2019. N Engl J Med, 382(8):727-733. https://doi.org/10.1056/NEJMoa2001017

Zhu Z, Lu ZH, Xu TM, et al., 2020. Arbidol monotherapy is superior to lopinavir/ritonavir in treating COVID-19. $J$ Infect, 81(1):e21-e23. https://doi.org/10.1016/j.jinf.2020.03.060 